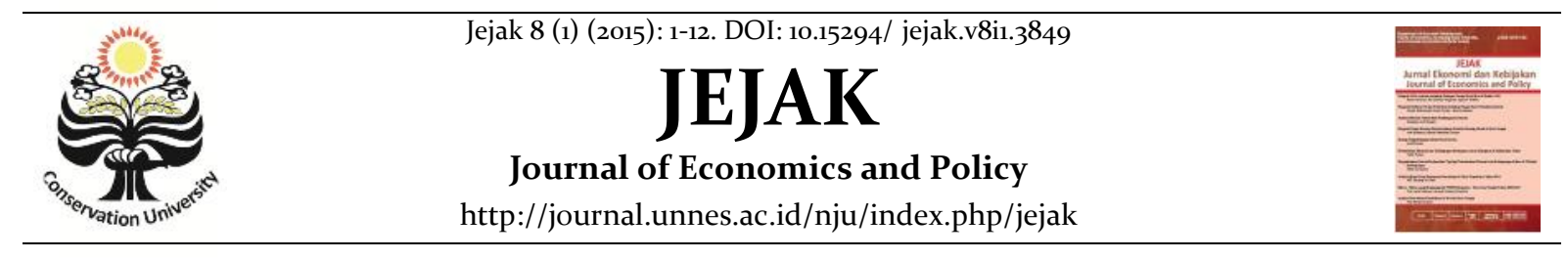

\title{
DAMPAK LNG ACADEMY TERHADAP KESIAPAN TENAGA KERJA BARU DI BADAK LNG
}

\author{
Agus M. Irkham ${ }^{\circledR}$, Busori Sunaryo ${ }^{2}$, Feri Sulistyo Nugroho ${ }^{3}$ \\ ${ }^{1}$ Universitas Diponegoro, Semarang, Indonesia \\ ${ }^{2}$ Manager Media, CSR, External Relation Badak LNG, Indonesia \\ ${ }^{3}$ Senior Manager Corporate Communication Badak LNG, Indonesia \\ Permalink/DOI: http://dx.doi.org/10.15294/jejak.v8i1.3849 \\ Received: 2 January 2015; Accepted: 26 january 2015; Published: March 2015
}

\begin{abstract}
LNG Academy is able to produce individuals (output) who have a considerably high link and match between education and industrial world. It also supports the governmental programs in reducing unemployment rates, especially the individuals graduated from university. It can also overcome the issue related to duration. Badak LNG Management Trainees, graduated from LNG Academy class, need only 6 months to pass the On Job Training as well as Job Specific Training. Whereas the MT graduated from outside the LNG Academy usually need 18 months in order to pass the trainings. It means that there are 12 months which can be saved (outcome). Since the early classes in the academy, the students have been introduced to the working ecosystem of the liquid natural gas company. Therefore, LNG Academy graduates who work for Badak LNG have no significant difficulty adapting with the working ecosystem, whether it is related to the working mechanism or other working cultures. In a short duration, they can be directly working-ready and understand how strategic it is the liquid natural gas business field in national and development issues (impact).
\end{abstract}

Keywords: Badak LNG, LNG Academy, Creating Shared Value

\begin{abstract}
Abstrak
LNG Academy diharapkan mampu menghasilkan individu yang memiliki kemampuan tinggi dan bisa memadukan antara pendidikan dan dunia industri. Hal ini juga mendukung program pemerintah dalam mengurangi tingkat pengangguran, terutama lulusan perguruan tinggi. Program management trainee di Badak LNG, lulusan dari LNG academy menbutuhkan waktu 6 bulan untuk melalui tahap pelatihan kerja serta pelatihan kerja khusus. Sedangkan lulusan program MT di luar LNG academy biasanya membutuhkan waktu 18 bulan untuk melalui masa training. Artinya ini akan menghemat 12 bulan. Sejak kelar perdana di kampus, siswa sudah diperkenalkan dengan lingkungan kerja pada perusahaan gas alam. Oleh karena itu, lulusan LNG academy yang bekerja di Badak LNG tidak menemukan kesulitan berarti saat beradaptasi dengan lingkungan kerja. Dalam jangka pendek mereka dapat langsung siap bekerja dan mengetahui betapa strategis dampak dari bisnis gas alam cair dalam peta pembangunan nasional.
\end{abstract}

Kata Kunci: LNG Badak, Akademi LNG, membuat nilai sharing

How to Cite: Irkham, A, Sunaryo, B., \& Nugroho, F. (2015). Dampak LNG Academy Terhadap Kesiapan Tenaga Kerja Baru di Badak LNG. JEJAK Journal of Economics and Policy, 8(1). 1-12

(c) 2015 Semarang State University. All rights reserved

\footnotetext{
Corresponding author :

Address: J1 Prof. Soedharto Tembalang Semarang

E-mail: agusirkham@gmail.com
}

ISSN 1979-715X 


\section{PENDAHULUAN}

Kebutuhan tenaga ahli di bidang gas alam cair di Indonesia maupun mancanegara semakin meningkat. Hal tersebut ditandai dengan banyaknya pembangunan kilang milik perusahaan gas alam cair mulai dari Statoil Norwegia, Qatargas, Mozambik LNG, Angola LNG, Yaman LNG, Dominion Cove USA,Donggi Senoro LNG, hingga BP Tangguh LNG.Namunpadasaat yang sama, ketersediaan tenaga ahli di bidang gas alam cair terbatas. Selain karena para tenaga ahli telah memasuki waktu purna tugas, hal ini juga disebabkan oleh penambahan "produksi" tenaga ahli di bidang gas alam cair juga lebih kecil dibandingkan dengan tingkat kebutuhannya. Tenaga ahli adalah representasi dari kemajuan sumberdaya manusia di satu Negara. Sedangkan di Negara berkembang permasalahan ini sering sekali muncul (Rena, 2009). Selain itu, isu gender juga ternyata menjadi permasalahan tersendiri terkait produktivitas tenaga kerja (Watson, 2010).

Di lain pihak, lembaga pendidikan (Perguruan Tinggi) yang diharapkan mampu mencetak sumber daya manusia yang siap masuk dunia kerja, termasuk ke sektor industri migas, hasilnya belum seperti yang diharapkan. Hal itu ditunjukkan dengan tingginya angka pengangguran yang justru persentase terbesar disumbang oleh kaum sarjana. Setiap tahunnya, sekitar 2.900 Perguruan Tinggi meluluskan tak kurang dari 300.000 sarjana. Jumlah sarjana menganggur di Indonesia pada 2010 mencapai 1.142.751 orang atau naik 15,71 \% dibandingkan dengan 2009. Atau secara absolut naik $600 \%$ dibandingkan tahun 2005 (183.629 orang).

Tulisan ini berisi kajian empiris dampak keberadaan $L N G$ Academy kaitannya dengan upaya menciptakan manfaat bersama (Creating Shared Value) yang dilakukan oleh
Badak LNG. Yaitu mengatasi kurangnya tenaga ahli di bidang gas alam cair, serta membantu pemerintah mengurangi angka pengangguran terutama akibat dari model pendidikan di perguruan tinggi yang memiliki keterkaitan dan kesepadanan (link and match) dengan kebutuhan industri masih rendah.

Ada tiga tujuan yang hendak dicapai dari kajian ini.Pertama, mengetahui seberapa jauh sistem atau mekanisme pengelolaan LNG Academy sebagai bentuk implementasi pendekatan Creating Shared Value sehingga mampu menciptakan manfaat bagi masyarakat maupun perusahaan. Kedua, mengetahui seberapa jauh output (lulusan) yang dihasilkan, serta outcome (efisiensi waktu) yang diperoleh Badak LNG serta peningkatan kapasitas berpikir para lulusan LNG Academy (impact) berupa kesadaran tentang gas alam cair yang memiliki kedududukan strategis dalam konteks isu kebangsaan dan proses pembangunan.

Melalui hasil kajian empiris yang didasarkan pada data sekunder, observasi lapangan, dan wawancara langsung terhadap pihak-pihak yang terlibat ini, penulis berharap dapat memberikan informasi dan pengetahuan bagi peneliti lain yang akan meneliti lebih jauh tentang LNG Academy kaitannya dengan implementasi Creating Shared Value di Badak LNG. Dari kajian ini juga diharapkan dapat menjadi bahan masukan atau input kebijakan terutama di bidang Pendidikan dan Ketenagakerjaan bagi pihak-pihak pemangku kepentingan pembangunan, terutama di Pemerintah Kota Bontang, Provinsi Kalimantan Timur serta Pemerintah Pusat. Selain itu, hasil kajian empiris ini dapat menjadi rujukan (adopsi dan modifikasi) bagi perusahaan lain ketika akan mendirikan lembaga pendidikan serupa $L N G$ Academy di daerah lain sebagai bagian 
dari upaya menciptakan manfaat bersama antara perusahaan dan masyarakat.

Ibarat seorang manusia, perusahaan merupakan makhluk hidup yang akan terus mengalami perkembangan. Ada tiga hal yang dapat menyebabkan perkembangan. Pertama, adanya tuntutan dan perubahan yang terjadi dari lingkungan luar perusahaan. Kedua, ekspektasi atau harapan perusahaan tersebut yang bertujuan untuk senantiasa memperbaiki kinerja perusahaan. Ketiga, konsekuensi logis dari entitas yang hidup sebab seiring berjalannya waktu kebutuhan akan meningkat dan untuk memenuhi peningkatan kebutuhan tersebut diperlukan penyesuaian-penyesuaian (adjustment) (Gray \& Ben, 2009).

Karena perusahaan adalah sebuah entitas yang hidup, maka ia tidak berada dalam lingkungan bebas nilai atau steril dari perkembangan yang sedang berlangsung di luar perusahaan.Termasuk pemahaman terhadap kaidah bisnis adalah bisnis (business is business). Kini banyak praktisi bisnis dan para ahli teori bisnis menemukan fakta menarik bahwa bisnis yang hanya berorientasi terhadap penumpukkan kapital atau keutungan ekonomi dengan mengabaikan nilai-nilai etika terutama terhadap persoalan sosial yang terjadi di sekitar lokasi perusahaan cepat atau lambat akan menghancurkan perusahaan itu sendiri.

Kesadaran perusahaan tentang persoalan-persoalan ekonomi, sosial, dan lingkungan yang terjadi di luar perusahaan akan turut serta menentukan eksistensi dan perkembangan perusahaan memunculkan satu konsep pendekatan atau strategi relasi perusahaan-lingkungan sosial yaitu Corporate Social Responsibility atau tanggung jawab sosial perusahaan(Card et al, 2011).
CSR dapat diartikan kepedulian para pengelola suatu perusahaan berkenaan dengan konsekuensi sosial, lingkungan, politik, manusia, dan keuangan atas tindakan-tindakan yang mereka ambil. Di dalam pelaksanaannya, diharapakan agar unsur-unsur perusahaan, pemerintah dan masyarakat saling berinteraksi dan mendukung, supaya CSR dapat diwujudkan secara komprehensif, sehingga dalam pengambilan keputusan, menjalankan keputusan dan pertanggungjawabannya dapat dilaksanakan bersama.

Menurut the world business council for sustainable development (WBCSD) in (Fox, et al, 2002), definisi CSR adalah:

"Corporate social responsibility is the continuing commitment by business to be have ethically and contribute to economic development while improving the quality of life of the workforce and their families as well as of the local community and society at large".

Komitmen bisnis untuk berkontribusi dalam pembangunan ekonomi berkelanjutan, bekerja dengan para karyawan perusahaan, keluarga karyawan tersebut, berikut komunitas-komunitas setempat (lokal) dan masyarakat secara keseluruhan dalam rangka meningkatkan kualitas kehidupan.

Peningkatan kualitas kehidupan mempunyai arti adanya kemampuan manusia sebagai individu anggota masyarakat untuk dapat menanggapi keadaan sosial yang ada dan dapat menikmati serta memanfaatkan lingkungan hidup termasuk perubahan-perubahan yang ada sekaligus memelihara. Atau dengan kata lain CSR merupakan cara dunia industri mengatur proses usaha untuk memproduksi dampak positif bagi masyarakat. 
Sedangkan Trinidad and Tobago Bureau of Standards (TTBS) menyatakan bahwa CSR diartikan sebagai komitmen usaha untuk bertindak secara etis, beroperasi secara legal dan berkontribusi untuk peningkatan ekonomi bersamaan dengan peningkatan kualitas hidup dari karyawan dan keluarga, komuniti lokal dan masyarakat secara lebih luas.Menurut Word Bank, CSR adalah komitmen dunia usaha untuk memberikan kontribusi bagi pembangunan ekonomi yang berkelanjutan bekerjasama dengan tenaga kerja dan organisasi representasinya, dengan masyarakat lokal dan dengan masyarakat dalam lingkup yang lebih luas, untuk memperbaiki kualitas hidup dengan cara yang menguntungkan kedua belah pihak baik untuk dunia usaha maupun untuk pembangunan.

Dari hasil CSR Meeting Changing Expectations, melihat CSR sebagai komitmen yang berkesinambungan dari kalangan bisnis untuk berperilaku secara etis dan memberi kontribusi bagi perkembangan ekonomi seraya meningkatkan kualitas kehidupan dari karyawan dan keluarganya serta komunitas lokal dan masyarakat luas pada umumnya. World Business Council for Sustainable Development mendefiniskan Corporate Social Responsibility sebagai komitmen berkelanjutan kalangan bisnis untuk berperilaku etis dan memberikan sumbangan pada pembangunan ekonomi sekaligus memperbaiki mutu hidup angkatan kerja dan keluarganya serta komunitas lokal dan masyarakat secara keseluruhan (Munck, 2010).

CSR Forum mendefinikan Corporate Social Responsibility sebagai bisnis yang dilakukan secara transparan dan terbuka serta berdasarkan pada nilai-nilai moral dan menjunjung tinggi rasa hormat kepada karyawan, komunitas dan lingkungan. Perusahaan yang menjalankan model bisnisnya dengan berpijak pada prinsipprinsip etika bisnis dan manajemen pengelolaan sumber daya alam yang strategik dan sustainable akan dapat menumbuhkan citra positif serta mendapatkan kepercayaan dan dukungan dari masyarakat.

Jadi, dapat kita simpulkan bahwa Corporate Social Responsibility adalah komitmen perusahaan untuk memberikan kontribusi jangka panjang terhadap satu issue tertentu di masyarakat atau lingkungan untuk dapat menciptakan lingkungan yang lebih baik. Kontribusi dari perusahaan ini bisa berupa banyak hal, misalnya : bantuan dana, bantuan tenaga ahli dari perusahaan, bantuan berupa barang, dan lain-lain.

Kegiatan CSR semula lebih banyak bersifat charity atau amal. Kemudian bergeser ke arah pemberdayaan masyarakat atau lazim dikenal dengan istilah community developement atau comdev. Comdev dilaksanakan oleh perusahaan dengan mengacu pada nilai keadilan dan kesetaraan atas kesempatan, pilihan partisipasi, timbal balik, dan kebersamaan.

Tujuan terjauh dari CSR adalah berupa transformasi perusahaan yang semula bersifat "private" menjadi Corporate Citizenship.The World Economic Forum mendefinisikan Corporate Citizenship sebagai:

"The contribution a company makes to society through its core business activities, its social investment and philanthropy programmes, and its engagement in public policy. The manner in which a company manages its economic, social and environmental relationships, as well as those with different stakeholders, in particular shareholders, employees, customers, business, partners, governments and communities determines its impact." 
Ada pergeseran orientasi institusi bisnis dan perusahaan dalam program CSR yang semula bersifat donasi (Charity), ke keterlibatan masyarakat, bahkan meningkat lagi ke fase "perusahaan warga" (Corporate Citizenship).

CSR diartikan sebagai:

“...that a corporation should be held accountable for any of its actions that affect people, their communities, and their environment. It implies that negative business impacts on people and society should be acknowledged and corrected if at all possible. It may require a company to forgo some profits if its social impacts are seriously harmful to some of its stakeholders or if its funds can be used to promote a positive social good."

Kenneth Dayton, mantan pemimpin perusahaan The Dayton-Hudson Corporation mengatakan bahwa dalam bisnisnya ia tidak dalam kondisi mencetak laba maksimal tapi dalam bisnis yang memberikan pelayanan pada masyarakat. Laba yang diperolah adalah hadiah atas upaya itu.

"We are not is business to make maximum profit for our shareholders. We are in business...to serve society. Profit is our reward for doing it well. If business does not serve society, society will not long tolerate our profit or even our existence."

Perkembangan CSR hakikatnya sangat dipengaruhi oleh perkembangan yang berlangsung di masyarakat. Salah satunya adalah berkaitan dengan hubungan atau relasi antar individu (personalize) dan komunitas (community). Secara kategoris, pergeseran pendekatan dalam program CSR menyangkut tujuan, pendekatan, dan lingkup program untuk masyarakatdalam konteks relasi antar individu dan komunitas itudapat dibaca pada tabel 1 berikut ini.

Tabel 1. Perbedaan Karakteristik antaraPendekatan Hubungan Masyarakat yang Lama dan Baru

\begin{tabular}{|c|c|c|c|}
\hline & $\begin{array}{l}\text { Charitable donations } \\
\text { (prior 1980) }\end{array}$ & $\begin{array}{l}\text { Community involvement } \\
(1980-1990)\end{array}$ & $\begin{array}{l}\text { Corporate citizenship } \\
\text { (1990-present) }\end{array}$ \\
\hline Objectives & $\begin{array}{l}\text { Goodwill (with local } \\
\text { community leaders } \\
\text { and resident } \\
\text { employees) }\end{array}$ & $\begin{array}{l}\text { Reputation as employer } \\
\text { of choice (with resident } \\
\text { employees) }\end{array}$ & $\begin{array}{l}\text { Trust and legitimacy } \\
\text { (across stakeholders in } \\
\text { the community) }\end{array}$ \\
\hline $\begin{array}{l}\text { Scope of } \\
\text { community } \\
\text { programmes }\end{array}$ & $\begin{array}{l}\text { Charitable donations } \\
\text { to local charities and } \\
\text { causes }\end{array}$ & $\begin{array}{l}\text { Employee volunteer } \\
\text { programmes, growing } \\
\text { involvement in social } \\
\text { welfare programmes }\end{array}$ & $\begin{array}{l}\text { Partnerships with local } \\
\text { public institutions in } \\
\text { bettering the } \\
\text { community and } \\
\text { increasing welfare. }\end{array}$ \\
\hline $\begin{array}{l}\text { General } \\
\text { approach }\end{array}$ & $\begin{array}{l}\text { Idiosynratic } \\
\text { implementation } \\
\text { dependent on } \\
\text { requests from } \\
\text { community leaders } \\
\text { or managers personal }\end{array}$ & $\begin{array}{l}\text { Specific approach of } \\
\text { fostering productive } \\
\text { workplace, linked to } \\
\text { competitive goals. }\end{array}$ & $\begin{array}{l}\text { Wide-ranging approach } \\
\text { driven by mission, } \\
\text { values and wider range } \\
\text { of stakeholders }\end{array}$ \\
\hline
\end{tabular}


networks

Sumber. Joep Cornelissen, Corporate Communication-A Guide to Theory and Practice. Third Edition, SAGE Publication Asia-Pacific Pte Ltd, Singapore, 2011. p. 243

Tujuan, pendekatan dan lingkup sebagai "Matabaru" CSR. Tabel 2 program CSR yang mengarah pada Corporate menunjukkan prinsip-prinsip dasar Citizenship inilah yang penulis maksudkan "matabaru" tersebut.

Tabel 2. Prinsip-Prinsip Dasar "Matabaru" Corporate Social Resonsibility

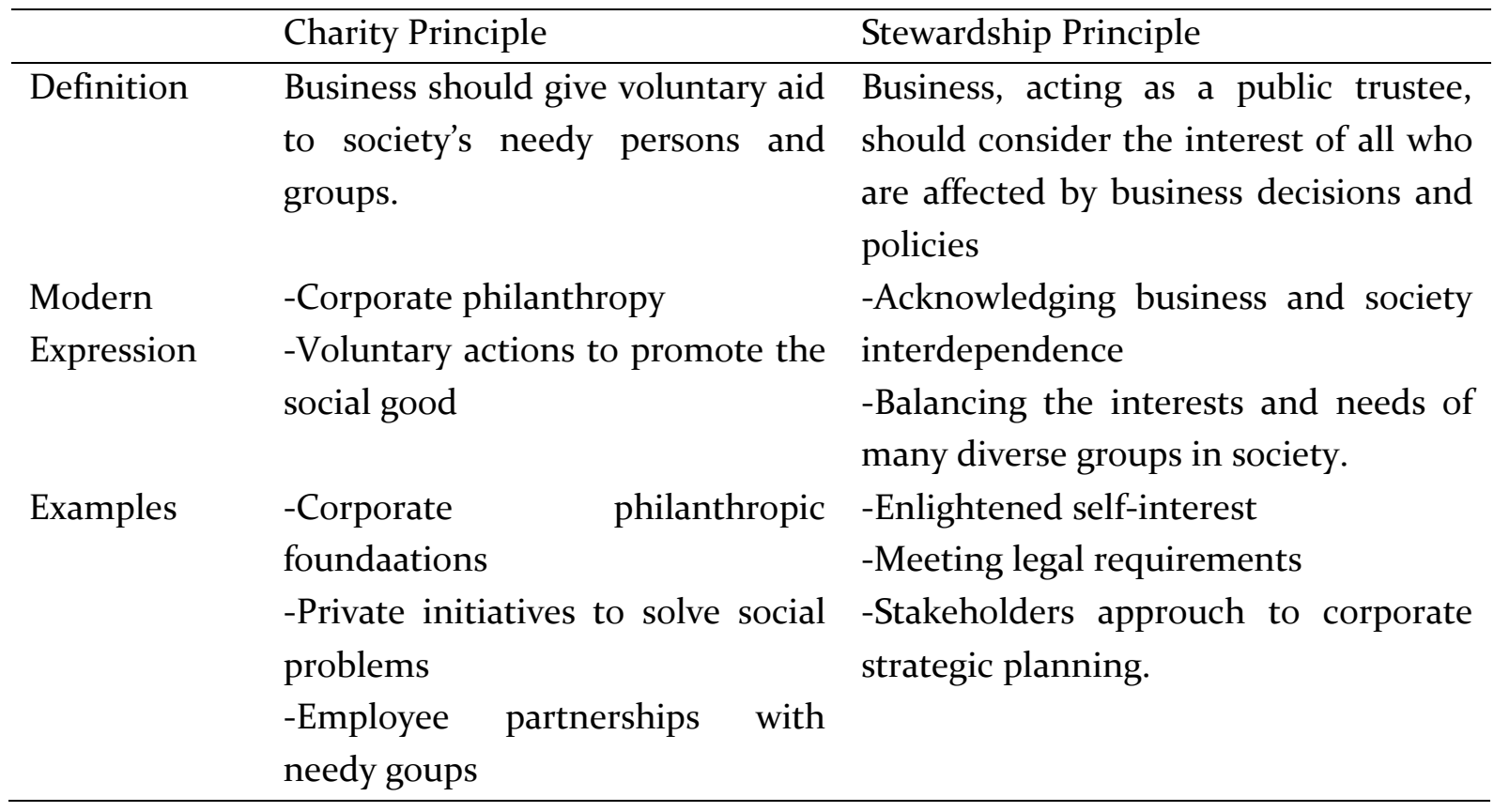

Konsep Corporation Citizenship secara subtansi sama dengan konsep Triple Bottom Line yang dipopulerkan oleh John Elkington pada tahun 1997 melalui bukunya "Cannibals with Forks". Elkington mengembangkan konsep triple bottom line dalam istilah economic prosperity, environmental quality, dan social justice.

Melalui buku tersebut, Elkington memberi pandangan bahwa perusahaan yang ingin berkelanjutan, haruslah memperhatikan "3P". Selain mengejar keuntungan (profit), perusahaan juga mesti memperhatikan dan terlibat pada pemenuhan kesejahteraan masyarakat (people), dan turut berkontribusi aktif dalam menjaga kelestarian lingkungan (planet).
Selayaknya ilmu pengetahuan, konsep CSR tersebut tak luput dari beragam keberatan dan kritik (antitesis). Ada dua kritik bagi konsep ini yakni program CSR dikatakan tidak ada keterkaitannya secara langsung dengan kegiatan perusahaan karena perusahaan dan lingkungan-sosial bersifat independent, tidak saling mempengaruhi satu sama lain. Selain itu, meskipun ada banyak anjuran agar mengintegrasikan CSR dalam strategi, pada kenyataannya CSR masih dipandang sebagai cost atau biaya yang harus dikeluarkan perusahaan.

Kritik tersebut melahirkan konsepsi baru (sintesa) yaitu Creating Shared Value. Adalah Profesor Michael Porter dari Harvard Business School dan Mark Kramer, seorang konsultan ternama yang memperkenalkan 
istilah tersebut di Harvard Business Review dalam artikel berjudul The Big Idea Creating Shared Value pada awal 2011. Porter dan Kramer menganjurkan agar ada integrasi menyeluruh antara lingkungan sosial dan perusahaan sehingga ada hubungan yang saling mempengaruhi. Kemajuan sosial merupakan kemajuan perusahaan juga. Oleh karena itu, tak heran jika integrasi sosial dan bisnis untuk menciptakan shared values harus terjadi di level business model, bukan lagi di tingkat strategi perusahaan sehingga CSR tidak lagi menjadi biaya bagi perusahaan.

Ada tiga cara untuk mewujudkan manfaat bersama tersebut. Pertama dengan melakukan redefinisi pasar dan produk. Kedua, mencari batasan-batasan pengertian baru tentang produktivitas sepanjang rantai nilai (value chain). Rantai nilai adalah aktivitas atau kegiatan dalam sebuah perusahaan yang dilakukan untuk mendisain, memproduksi, memasarkan, mengirimkan dan support produk. Konsep rantai nilai pertama kali dikenalkan dan dipopulerkan oleh Michael E. Porter pada tahun 1985. Ketiga, membangun klaster industri pendukung. Ketiga cara tersebut bertemu dalam satu titik tujuan yaitu meningkatkan kualitas hidup manusia secara keseluruhan.

Ada dua aktivitas pada rantai nilai atau value chain yaitu aktivitas utama dan aktivitas pendukung. Aktivitas utama terdiri atas logistik, operasional, logistik keluar, pemasaran dan penjualan, serta pelayanan. Sedangkan aktivitas pendukung terdiri dari procurement, technology development, human resource management, dan firm infrastructure.

Atas dasar pemahaman tentang evolusi perkembangan konsep CSR yang kemudian bergeser ke CSV, lantas dihadapkan pada persoalan sosial pendidikan dan segenap potensi yang dimiliki serta ekspektasi atas perkembangan industri migas sebagaimana yang telah tertulis di bagian pendahuluan tulisan ini, maka Badak LNG mendirikan LNG Academy.

\section{METODE PENELITIAN}

Penelitian ini menggunakan data primer berupa wawancara langsung terhadap para pihak-pihak yang terlibat dan berkepentingan (stakeholders). Selain data primer,penulisjugamemanfaatkan data sekunder serta studi kepustakaan dengan mencari literatur pendukung yang berkaitan dengan masalah penelitian ini. Data yang digunakan dalam penelitian ini adalah data sekunder yang diperoleh dari beberapa sumber, yaitu (1) Corporate Communication Badak LNG; (2) LNG Academy; (3) Badan Pusat Statistik Kota Bontang; dan (5) Dinas Sosial dan Tenaga Kerja Kota Bontang

Metode analisis yang digunakan dalam penelitian ini ada dua. Pertama, metode analisis kuantitatif. Metode ini mengkaji dan menganalisis setiap data yang berhasil dikumpulkan. Kedua, metode analisis kualitatif. Metode ini didasarkan pada hasil analisis data kuantitatif yang kemudian dikaitkan dengan data yang diperoleh dari hasil observasi dan wawancara guna mendapatkan kejelasan terhadap suatu fakta. Sehingga akan diperoleh penjelasan baru sekaligus penguatan terhadap suatu gambaran yang sudah ada. Jadi bentuk analisis ini bukan berupa angka-angka statistik atau bentuk angka lainnya.

\section{HASIL DAN PEMBAHASAN}

Politeknik dalam pendidikan di Indonesia merupakan salah satu bentuk perguruan tinggi selain akademi, institut, sekolah tinggi, dan universitas. Politeknik 
menyelenggarakan pendidikan vokasi dalam sejumlah bidang pengetahuan khusus.

Untuk mencapai tujuan tersebut, politeknik memberikan pengalaman belajar dan latihan yang memadai untuk membentuk kemampuan profesional di bidang ilmu pengetahuan dan teknologi.

Dalam kedudukannya sebagai perguruan tinggi, politeknik merupakan bagian dari sistem pendidikan nasional yang bertujuan menyiapkan mahasiswa menjadi anggota masyarakat yang memiliki kemampuan pofesional yang dapat menerapkan, mengembangkan, dan menyebarluaskan ilmu pengetahuan dan teknologi serta mengupayakan penggunaannya untuk meningkatkan taraf kehidupan masyarakat dan kesejahteraan umat manusia serta memperkaya kebudayaan nasional.

Politeknik atau sering disamakan dengan institut teknologi adalah penamaan yang digunakan dalam berbagai institusi pendidikan yang memberikan berbagai jenis gelar dan sering beroperasi pada tingkat yang berbeda-beda dalam sistem pendidikan. Politeknik dapat merupakan institusi pendidikan tinggi dan teknik lanjutan atau pendidikan vokasi profesional, yang memiliki spesialiasi dalam bidang ilmu pengetahuan, teknik, dan teknologi atau jurusan-jurusan teknis yang berbeda jenis. Istilah tersebut juga dapat merujuk pada sekolah pendidikan menengah yang berfokus pada pelatihan vokasional.

Pertama, Politeknik Negeri Jakarta.Sejarahnya bermula dari fakultas non gelar teknologi Universitas Indonesia (FNGTUI), yang kemudian menjadi Politeknik Universitas Indonesia.Politeknik Universitas Indonesia didirikan 20 September 1982, sejak 25 Agustus 1998 menjadi mandiri dengan nama Politeknik Negeri Jakarta.
Ketika didirikan, dibuka 3 jurusan: Jurusan Teknik Mesin, Teknik Sipil dan Teknik Elektro. Menyusul tahun 1986 dibuka jurusan Tata Niaga, yang selanjutnya dikembangkan menjadi Jurusan Akuntansi dan Jurusan Administrasi Niaga. Pada tahun 1990 dibuka Jurusan Teknik Grafika dan Penerbitan, hasil kerjasama antara Politeknik Universitas Indonesia (Politeknik Negeri Jakarta) dengan Pusat Grafika Indonesia. Kemudian bekerjasama dengan PT Trakindo Utama, dibuka Program Studi Alat Berat dibawah Jurusan Teknik Mesin yang dimulai tahun ajaran 2001-2002.

Politeknik Negeri Jakarta (PNJ) merupakan lembaga pendidikan tinggi Diploma III yang didirikan untuk memenuhi kebutuhan SDM profesional di industri, baik industri jasa maupun industri manufaktur. Pembelajaran di PNJ mengaplikasikan Kurikulum Nasional (Kurnas) pendidikan profesional secara bertanggung jawab dengan didukung oleh dosen-dosen profesional. Sistemnya adalah dengan mempertemukan ilmu dan teknologi sesuai komposisi teori $55 \%$ dan praktek $45 \%$ yang diaplikasikan secara harmonis untuk menghasilkan lulusan yang profesional dan memenuhi kualifikasi industri.Menghasilkan tenaga kerja yang memiliki keahlian vokasi sesuai bidangnya dan mampu bersaing di tingkat internasional.

LNG Academy adalah program pendidikan jenjang Diploma III (D-3) kerjasama antara Badak LNG dan Politeknik Negeri Jakarta (PNJ). Dimulai sejak tahun akademik 2011-2012, program ini berada pada Jurusan Teknik Mesin - Program Studi Teknik Konversi Energi - Konsentrasi Teknik Pengolahan Gas danmemiliki 3 (tiga) peminatan studi yaitu : (1) Teknik Pengolahan Gas; (2) Teknik Perawatan Mekanikal dan Rotating; (3) Teknik Perawatan Listrik dan Instrumentasi. Ketiga 
jenis peminatan tersebut mengacu pada kebutuhan operasional utama kilang gas alam cair.Setiapangkatan, LNG Academymenerima $\quad 20-30 \quad$ orang pesertadidikdengankuota calon mahasiswa yang diterima dari Kalimatan Timur sekitar 30\%.Namun, persentase tersebut tidak bersifat pasti dan wajib karena tetap dengan mengacu hasil tes.

LNG Academy memiliki visi menjadi menjadi pusat keunggulan (center of excellence) dan rujukan pendidikan keteknikan di bidang LNG yang mampu menghasilkan lulusan yang profesional dan kompeten di bidang pengoperasian dan perawatan kilang LNG serta diakui pelaku bisnis LNG di dunia. Visi tersebut dicapai melalui pelaksanaan lima misi. Pertama, menyelenggarakan proses pendidikan dan pembelajaran secara menyeluruh agar peserta didik dapat menjadi praktisi/akademisi yang tidak hanya profesional dan bermutu secara akademis,tetapi juga memiliki akhlak, martabat, dan integritas yang tinggi.

Kedua, melestarikan, mewariskan, menyebarluaskan dan mengembangkan ilmu pengetahuan dan teknologi dibidang pengoperasian dan perawatan kilang LNG secara berkelanjutan. Ketiga, menjalin dan mengembangkan kerjasama yang luas dengan institusi pendidikan tinggi lain maupun pelaku bisnis industri LNG di dalam ataupun luar negeri. Keempat, melakukan evaluasi secara teratur terhadap kualitas, profesionalitas, kapabilitas, akuntabilitas, tata kelola dan kemandirian guna tercapainya perbaikan berkelanjutan dalam penyelenggaraan proses pendidikan. Kelima, melaksanakan program Pengabdian kepada Masyarakat sebagai upaya peran aktif membantu mengatasi masalah bangsa di dalam bidang pendidikan, ekonomi, sosial, dan budaya.

Pendirian LNG Academy dilatarbelakangi oleh dua faktor yaitu faktor internal dan eksternal. Termasuk ke dalam faktor internal adalah pertama, tingginya kebutuhan tenaga kerja di Badak LNG, baik disebabkan oleh adanya penggantian pekerja yang sudah purna tugas atau pensiun maupun karena banyaknya pekerja yang dipinjam sementara oleh perusahaan LNG lainnya. Kedua, Badak LNG memiliki fasilitas seksi pelatihan (Badak LNG Learning Center) yang digunakan untuk pelatihan calon pegawai maupun program pelatihan lainnya. Ditunjang pula dengan keberadaan para tenaga ahli (expertise) di bidang gas alam cair.

Sedangkan faktor eksternal meliputi pertama, permintaan tenaga kerja dari perusahaan LNG lain di seluruh dunia seperti Qatar Gas dan Statoil Norwegia. Kedua, banyak permintaan pelatihan dari perusahaan LNG lain. Mulai dari BP Tangguh LNG, Yaman LNG, Angola LNG, Mozambik LNG, hingga Donggi Senoro LNG. Ketiga, tingginya permintaan keahlian LNG yang disebabkan oleh pembentukan kilang LNG baru di seluruh dunia. Keempat, menjadi bagian dari ikhtiar Badak LNG untuk berkontribusi pada proses pembangunan nasional, terutama melalui pendidikan. Kelima, turut menjadi solusi terhadap masalah klasik pembangunan yaitu berupa tingginya angka pengangguran terdidik di Indonesia.

Penyusunan kurikulum pada $L N G$ Academy sesuai dengan standar jurusan teknis mesin ditambah beberapa matakuliah yang disesuaikan dengan kebutuhan di kilang.Penambahanmatakuliahtersebutbertuj uan memperkaya pengetahuan, pemahaman, 
dan penguasaan keterampilan agar hasilnyasesuai dengan yang diharapkan yaitu memenuhi kualifikasi keahlian bekerja di perusahaan migas khususnya gas alam cair.

Hingga akhir tahun 2014, LNG Academy telah meluluskan 22 mahasiswa. Para wisudawan tersebut adalahmahasiswa angkatan pertama. Semuanya lulus dengan Indeks Prestasi Komulatif (IPK) di atas 3,60. Bahkan salah satu lulusan $L N G$ Academymemperoleh IPK hampir sempurna, yaitu 3,96. Ia menjadi wisudawan terbaik dari 1.6oo wisudawan PNJ. Dari semua lulusan pertama, satu orang melanjutkan kuliah strata satu di Universitas Indonesia, sedangkan 21 orang lainnya bekerja di Badak LNG. Mereka ditempatkan di Departemen Operation, Maintenance, dan IT (Information Technology).

Meskipun LNG Academy merupakan program beasiswa penuh, Badak LNG tidak memberlakukan sistem ikatan dinas bagi para alumninya. Mereka yang ingin bekerja di Badak LNG tetap harus melalui serangkaian tes penerimaan pekerja baru, sama seperti para pelamar yang berasal dari perguruan tinggi lainnya.
Lolosnya para alumni LNG Academy ini bekerja di Badak LNG merupakan ukuran betapa kehadiran LNG Academy memang telah berhasil "mencetak" lulusan yang memiliki kompetensi susuai dengan kebutuhan perusahaan. Hal ini juga menunjukkan bahwa kebutuhan Badak LNG terhadap tenaga kerja baru cukup besar.

Setelah diterima menjadi pekerja di Badak LNG, alumni LNG Academy secara empiris memang memiliki keunggulan tersendiri. Salah satunya dari segi waktu yang diperlukan sebagai Management Trainee (MT). Lulusan LNG Academy tidak banyak mendapat materi di kelas, hanya sekitar seminggu. Adapun peserta MT umumnya bisa mendapat materi hingga tiga minggu karena belum memiliki landasan pengetahuan mengenai LNG.

Alumni LNG Academy juga tidak mengalami fase On the Job Training. Untuk mencapai posisi Job Specific Training, mereka membutuhkan waktu selama enam bulan. Padahal, secara umum posisi tersebut baru bisa dicapai peserta $M T$ setelah 18 bulan. Jadi dari segi waktu, alumni $L N G$ Academy mampu menghemat waktu selama 12 bulan.

Tabel 3. Manfaat Bersama (Creating Shared Value)Keberadaan LNG Academy

\begin{tabular}{ll}
\hline Stakeholder & Manfaat \\
\hline Perusahaan & Ketersediaan tenaga kerja yang sesuai dengan kualifikasi \\
& (hard skill $\mathcal{E}$ soft skill) di perusahaan migas khususnya gas \\
& alam cair \\
& Penghematan waktu bagi pekerja baru (Management \\
& Trainee) \\
& Penyerapan angkatan kerja baru \\
& Tidak menciptakan angka pengangguran baru \\
Pemerintah & Meningkatkan keterkaitan dan kesepadanan (link and \\
& match) antara dunia pendidikan dan industri. \\
Kesempatan perbaikan kualitas sumber daya manusia di \\
daerah khususnya di Kota Bontang dan Propinsi \\
Kalimantan Timur \\
Dapat berkontribusi langsung mengelola sumber daya alam
\end{tabular}

Sumber: Corporate Communication Badak LNG; LNG Academy. Diolah. 
Tidak hanya dari sisi efisiensi waktu, kinerjanya pun tergolong bagus. Proses penyesuaian diri alumni $L N G$ Academy termasuk cepat, begitu pula dengan standar kerja LNG safety-nya. Hal ini disebabkan oleh sistem sistem perkuliahan di $L N G$ Academyberupa 6o \% praktik dan $40 \%$ teori. Saattidakadaperkuliahanatauada jam kosong, mahasiswa dibawa ke area operasi sehingga mengetahui langsung pekerjaan di lapangan. Sebelum lulus, mereka juga mengikuti kerja praktik atau magang. Dengan demikian, dalam jangka waktu yang tidak terlalu lama mereka dapat mengikuti kultur dan ekosistem kerja.

\section{KESIMPULAN}

Kehadiran LNG Academysecara empiris telah berhasil menciptakan manfaat bersama (Creating Shared Value) yakni menciptakan energi muda pembangun bangsa.Ada tiga stakeholders yang memetik manfaat dari kehadiran LNG Academy tersebut. Pertama adalahpemerintah, menyangkut aspek ekonomi berupa penyerapan angkatan kerja baru, dan usaha menekan angka pengangguran, serta aspek sosial-pendidikan yaitu meningkatkan keterkaitan dan kesepadanan (link and match) antara dunia pendidikan dan industri.

Stakeholders kedua, perusahaan migas baik di Indonesia maupun dunia, terutama Badak LNG. Para lulusan LNG Academytelah memberikan kepastian ketersediaan tenaga kerja baru yang berkualitas. Tidak hanya dari segi hard skill atau keterampilan teknis, tapi juga social skill berupaattitude atau sikap kerja, kemampuan berkomunikasi dan bekerjasama dengan orang lain, sertaaspekaspek non teknis lainnya.

Stakeholdersketiga adalah masyarakat umum, khususnya masyarakat Kota Bontang dan Kalimatan Timur. Yaitu berupa terbukanya kesempatan untuk memperbaiki kualitas sumber daya manusia lokal serta dapat berkontribusi langsung dalam pengelolaan sumber daya alam.

\section{DAFTAR PUSTAKA}

Card, David. et al. (2011). The Labor Market Impacts of Youth Training in the Dominican Republic. Journal of Labor Economics, 2011, vol. 29, no. 2

Cornelissen, Joep. (2011). Corporate Communication-A Guide to Theory and Practice. Third Edition. Singapore: SAGE Publication Asia-Pacific Pte Ltd.

Gray, Matthew., and Ben Edwards. (2009). Determinants of the Labour Force Status of Female Carers. Australian Journal of Labour Economics Volume 12 Number 12009 pp 5-20

Margiono, M. Ari. (2011). Melirik Paradigma Creating Shared Value. Bisnis Indonesia, Minggu 1 Mei 2011.

Munck, Ronaldo P. (2010). Globalization and the Labour Movement: Challenges and Responses. Global Labour Journal. Vol. 1 No 2

Porter, M. E (1998). Competitive Advantage: Creating and Sustaining Superior. New York: Free Press.

Rena, Ravinder. (2009). The Child Labor in Developing Countries: A Challenge to Millennium Development Goals. Indus Journal of Management E Social Sciences, 3(1):1-8 (Spring 2009)

Sunaryo, Busori., \& Agus M. Irkham. (2015). PendarPendar Kepedulian: Kisah Pencapaian Badak LNG Meraih Proper Emas. Jakarta: Badak LNG

Undang-Undang Republik Indonesia Nomor 20 Tahun 2003 tentang Sistem Pendidikan Nasional.Jakarta

Watson, Ian. (2010). Decomposing the Gender Pay Gap in the Australian Managerial Labour Market. Australian Journal of Labour Economics, Volume 13 No 12010 pp 49 - 79 